\title{
Integration of Renewable Sources in the Electric System using Virtual Renewable Power Plants
}

\author{
Luis C. Rodrigues and Ana I. Estanqueiro \\ Laboratório Nacional de Energia e Geologia - LNEG \\ Lisbon, Portugal \\ Luis.rodrigues@lneg.pt, Ana.estanqueiro@lneg.pt
}

\begin{abstract}
The concept of "Virtual Renewable Power Plants VRPP" enables several positive factors for the electric integration of Renewable Energy Sources (RES), namely (a) the smoothing of time based fluctuation of the power delivered by the RES, (b) the use of the natural complementary of renewable resources availability (c) the establishment of synergies between different RES as well as the combination of their production. The present work aims to identify the synergies between wind and photovoltaic (PV) plants, regarding their daily profiles 1 complementarity and resource availability; as well as the technical and economic added value of a VRPP. Results show an increase of $5.3 \%$ in the capacity factor when $2 \mathrm{MWp}$ of $\mathrm{PV}$ is added to an $8 \mathrm{MW}$ wind farm, considering all infrastructural capacity limits. Moreover, additional results include the characterization and optimization of hybrid virtual wind-PV plants production profile.
\end{abstract}

Keywords- virtual power plant, power smoothing, RES power quality

\section{INTRODUCTION}

The large-scale integration of renewable energy sources (RES) generation in the electric network as well as the management of this relevant component of the actual power system poses serious challenges, both for system managers and for electric network planners.

The recent introduction of the "Virtual Renewable Power Plants - VRPP" concept enables several positive factors for the electric integration of these sources, namely (a) the smoothing of time based fluctuation of the power delivered by the RES (particularly accentuated in the case of wind energy), (b) the use of the natural complementary of renewable resources availability (c) the establishment of synergies between different RES as well as the combination of their production. The effective use of all identified RES synergies and complementarities through the establishment of the common electrical control systems that constitute the basis of a VRPP may permit the creation of merged daily production profiles more adapted to the load profiles than that of individual RES.

The present work will address a realistic case-study to identify the synergies between virtually combined wind and photovoltaic (PV) plants, regarding their natural complementarity and resource availability; as well as the technical and economic value of such a VRPP, not only from the system management, but also from the developer's point of view, since these synergies often represent a reduction in infrastructural needs and investments - i.e. interconnection transmission line, transformers and auxiliary equipment.

To enable future VRPP dynamic studies, time-domain models with the capacity to represent the detailed behavior of these plants were developed. Nevertheless, for the purpose of the present study, the models were assumed as quasi-stationery and applied to an existing wind power plant located in the central mountainous region of Portugal aiming to assess the benefit of adding PV or other RES local generation.

II. The Smoothing of Power Fluctuation AND The NATURAL COMPLEMENTARITY OF RENEWABLE RESOURCES

Fast fluctuations produced by the wind turbines generators (WTG) are mostly uncorrelated and tend to not be noticed by the Transmission System Operators (TSO) [1]. Local distribution networks also take advantage of the smoothing effect caused by the aggregation of production of WTG. The natural smoothing effect, as demonstrated by [1], obeys the Lipman relation [2]:

$$
\sigma\left(\mathrm{P}_{\mathrm{WP}}\right)=\sigma\left(\mathrm{P}_{\mathrm{WT}}\right) / \mathrm{N}^{1 / 2}
$$

where $\sigma\left(\mathrm{P}_{\mathrm{WP}}\right)$ represents the standard deviation of the aggregated output's power, $\sigma\left(\mathrm{P}_{\mathrm{WP}}\right)$ the standard deviation of an individual wind turbine and $\mathrm{N}$ the number of wind turbines.

Beyond the natural cancelation of fluctuations, active systems can be used, till a certain extent, for smoothing fast fluctuations. Such systems may be implemented on the turbine control itself (e.g. pitch angle control [3]), or may be commanded from a higher hierarchical level through the use of VRPP (e.g. wind energy curtailment or usage of rotor inertia to store the additional energy brought by a wind gust as kinetic energy for later conversion, as in [4]).

However, slower fluctuations are not naturally smoothed (in a country wide or control-zone scale) and imply the commitment of additional system reserves, generally supplied by non-renewable power plants. Therefore, if slower fluctuations can be smoothed out: (a) the capacity factor of the wind plants (among other fluctuating RES) may be proportionally increased when an external source of energy is used; (b) the added value of the power reserves may be reduced and (c) nonrenewable capacity is displaced.

The possibility of combining PV with existent wind farms is a solution that could effectively reduce these fluctuations [5]. The installation of PV in wind farms could also take advantage 
from the Portuguese legislation [6] that allows already existing wind farms to have $20 \%$ of installed capacity over its licensed limit (a.k.a. "overcapacity"). Therefore, the possibility of using this overcapacity with PV enables the opportunity to complement the wind generation in a synergic manner, and has the potential to present a high internal rate of return (IRR) of the investment.

When it comes to the PV installations, a similar behavior of natural cancelation of fast fluctuations is expected for solar-PV installations. For instance, smoothing of fast power fluctuation at a local scale $(4 \mathrm{~km})$ is reported by Otani et al [7] and even larger smoothing was obtained when taking into account 100 systems spread over Germany [8]. However, considering the same space scale, wind power presents a higher smoothing effect of power fluctuation. The explanation may be attributed to the fact that PV fast fluctuations are mostly caused by clouds [9], which have a more uniform effect over a larger spatial magnitude than wind turbulence.

In an effort to identify simple methods to tackle slow fluctuations of wind and solar resources, the correlation of both must be evaluated. Considering the daily period, while PV depends on day light, the night period is dominant in many wind power plant generation profiles [5]. For the annual period, the complementarity is stated considering large areas in [10], [11] and [12] but none of those studies considered the integration of wind and PV at a local scale $(0.5<\mathrm{d}<50 \mathrm{~km})$.

This study aims to describe and analyze the benefits of a VRPP through a hybrid wind/PV power plant and assess the added value obtained by increasing the capacity factor of the infra-structure.

\section{MethodOLOGY}

In order to evaluate the advantages obtained by implementing overcapacity by adding PV in a wind farm, a realistic case study was setup using time-domain models in a power system simulation tool (PSS/E). A one year data series of wind speed and irradiance in an existing wind farm site were used to feed the model.

The data input of the model is described in subsection A while the models used are described in subsection B.

\section{A. Input data}

Regarding the necessity of feeding each of the wind turbines with one wind series, a synthetic series needed to be generated. The baseline wind speed data at the hub height was measured as the average wind speed of every 30 minutes in a real wind farm site in central Portugal. The turbulence component, modeled with Davenport spectrum [13], [14], is added to interpolated wind speed for each simulation time step for each of the wind turbines as in:

$$
U_{k}(t)=U_{30}(t)+U_{\text {turb } k}(t)
$$

where: $U_{k}$ stands for the wind speed time series at the WTG $k$, $U_{30}$ is the interpolated measured mean speed for simulation time $t$ and $U_{\text {turb } k}$ is the turbulence component of the wind speed in the time step $t$ for the WTG $k$.

The global solar irradiance series to be used is a test reference year obtained for the optimal slope at the case study's location, with a resolution of 1 hour from SolTerm [15] database. Besides their different sampling rate, both the irradiation and the wind speed data series have a length of one year.

\section{B. Model description}

The time-depending models used in this case study can model adequately the dynamic characteristics of the RES, although the phenomenon of interest in the present study is quasi-stationary. Priority was given to the use of standard models from the platform library (PSS/E).

\section{1) WTG model}

For modeling the WTG: control, generator and mechanic, standard modules (fully described in [16]) were used. Wind input and aerodynamic modules were created and used as User Modules (USRMDL). Connectivity between modules is shown in Fig.1.

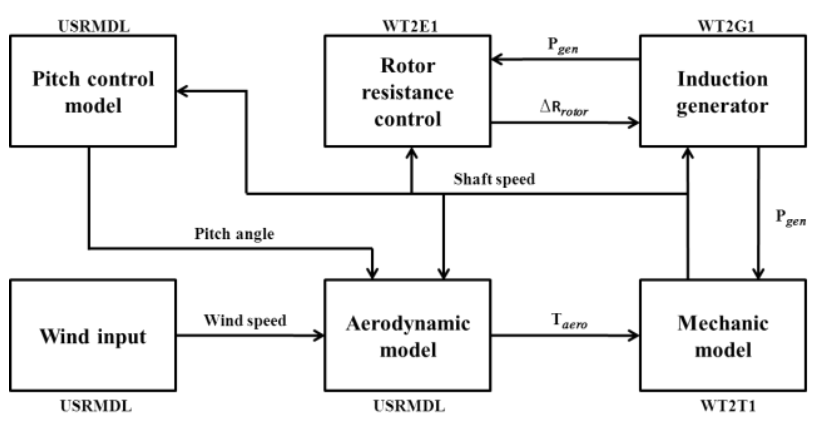

Figure 1. WTG model diagram (adapted from [16])

The turbine mechanical power output is defined [17] as:

$$
P_{\text {mec }}(t)=0.5 \rho A_{r} c_{p}(\lambda, \theta) U^{3}(t)
$$

where: $P_{m e c}$ is the extracted mechanical power [W], $\rho$ is the air density $\left[\mathrm{kg} / \mathrm{m}^{3}\right], A_{r}$ is the rotor swept area $\left[\mathrm{m}^{2}\right], c_{p}$ is the performance coefficient, $\lambda$ is the tip speed ratio or the ratio between the blade tip speed $U_{t}[\mathrm{~m} / \mathrm{s}]$ and wind speed at hub height upstream the rotor $U[\mathrm{~m} / \mathrm{s}]$.

A simple algebraic relation was used in order to model the rotor power coefficient characteristic, based in [18]:

$$
c_{p}(\lambda, \theta)=0.73\left(151 \Lambda_{i}-0.58 \theta-0.002 \theta^{2.14}-13.2\right) e^{-18.4 / \lambda i}
$$

with

$$
\lambda_{i}=\left((\lambda-0.02 \theta)^{-1}-0.003 /\left(\theta^{3}+1\right)\right)^{-1} .
$$

where $\theta$ is the pitch angle [degree].

In order to keep the simulation stable under high wind speeds, a proportional controller for the pitch angle is used, as depicted in Fig. 2. 


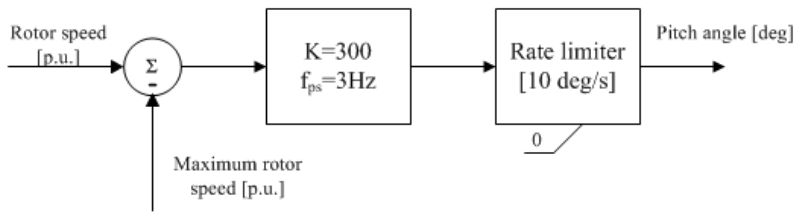

Figure 2. Pitch angle controller model.

\section{2) PV model}

The Solar PV model used simulates the performance of a PV plant connected to the grid via a power converter. As for the WTG model, preference was given for the use of standard library models [16]. In Fig. 3, the connectivity used between modules is depicted.

A PSS/E User Module is used to linearize and input a one year long irradiation series into the simulation.

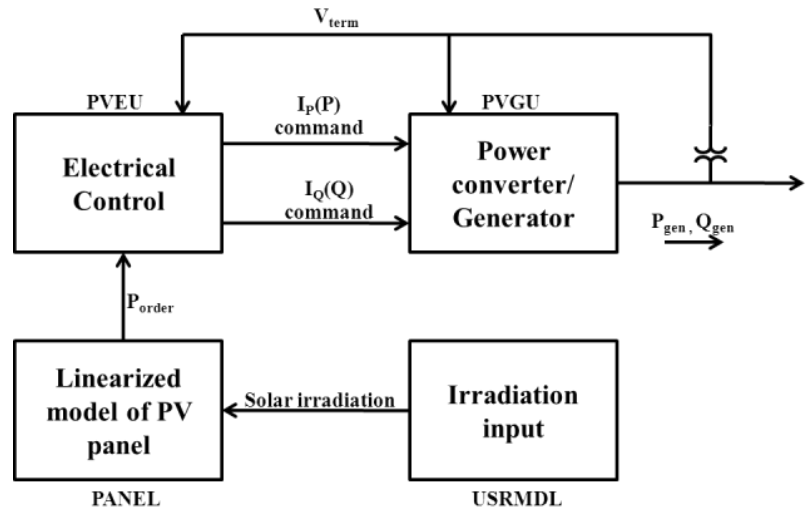

Figure 3. PV model diagram (adapted from [19])

The solar irradiation input is then converted linearly in a power order, following the characteristic shown in Fig. 4, by the PSS/E standard module PANEL. The power order is then sent to the electrical control module (PVEU) where the terminal voltage is considered in order to establish the active and reactive current command to the converter/generator module (PVGU) which by its turn delivers active and reactive power.

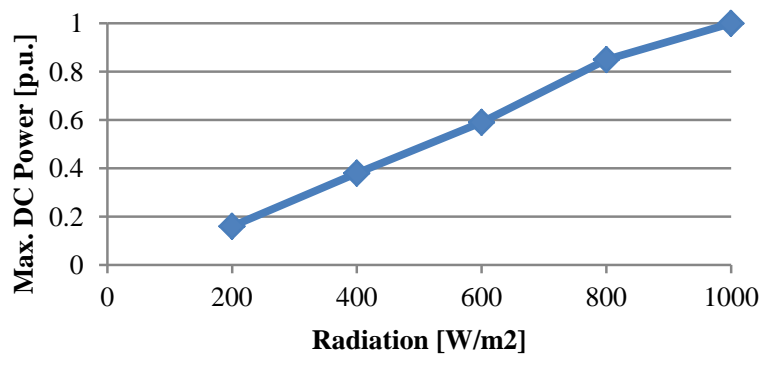

Figure 4. Typical solar panel power output characteristic

The studied wind farm grid topology is presented in Fig. 5, where four WTG (2.0 MW each) and an added PV overcapacity $(2 \mathrm{MWp})$ are shown.
Due to the WTG technology simulated, capacitors are added to each of the WTG terminals so as to fulfill reactive power needs. The hybrid wind farm is connected through an impedance corresponding to a short-circuit ratio $\approx 10$ to the infinite bus.

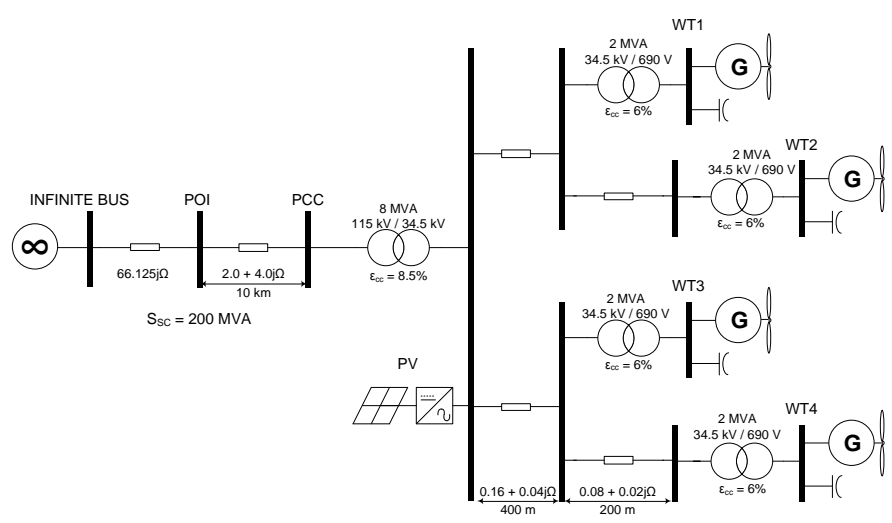

Figure 5. Hybrid wind/PV farm network diagram.

\section{RESULTS}

The capacity factor of the connection infrastructure is $24.0 \%$ when only wind is connected. When PV generation is added, the capacity factor raises to $29.3 \%$.

The hourly averaged daily profile of production obtained from the simulation and the average consumption profile for Portugal is presented in Fig.6. When comparing PV and WTG average generation profile, a negative correlation of -0.41 has been noticed, underlining their complementarity.

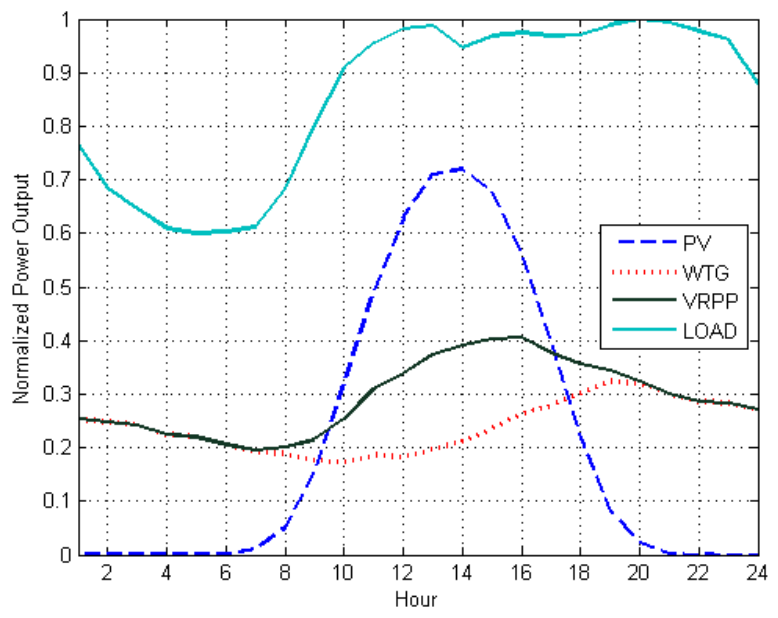

Figure 6. Average daily profile

In Table 1 are shown the correlations between the different sources and the daily profile. Data present a considerable better fit of the VRPP profile to the load profile against those of the individual sources (WTG and PV).

While the connection infrastructure takes benefit from the negative correlation between wind and PV resources, their 
higher correlation with the load profile when combined clearly benefits the Distribution System Operation (DSO).

TABLE I. CORRELATION BETWEEN AVERAGE LOAD DAILY PROFILE AND RES GENERATIONS DAILY PROFILES

\begin{tabular}{|c|c|}
\hline WTGs & 0.41 \\
\hline PV & 0.54 \\
\hline VRPP (merged WTGs and PV) & 0.82 \\
\hline
\end{tabular}

The normalized power for a typical day from the case study simulation is presented in Fig. 7. The increase in the capacity factor due to the PV addition is perceived as the difference between the red (WTG) and the dark green (VRPP) lines.

Fig. 8 compares the voltage profiles for a typical day for the VRPP with and without the PV generation. The difference between both profiles can be attributed to the additional reactive regulation provided by the PV system converter, which enhances the smoothing of voltage oscillations.

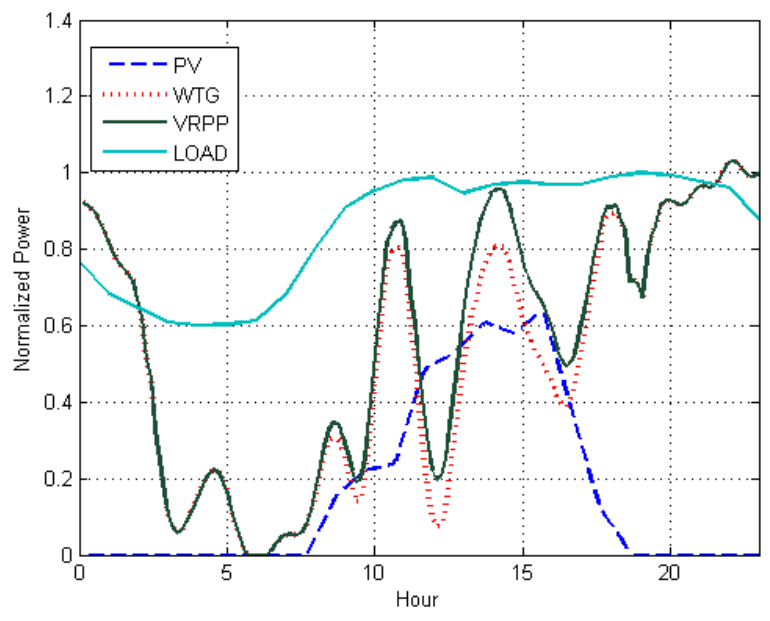

Figure 7. Power generation and load profile for a typical day

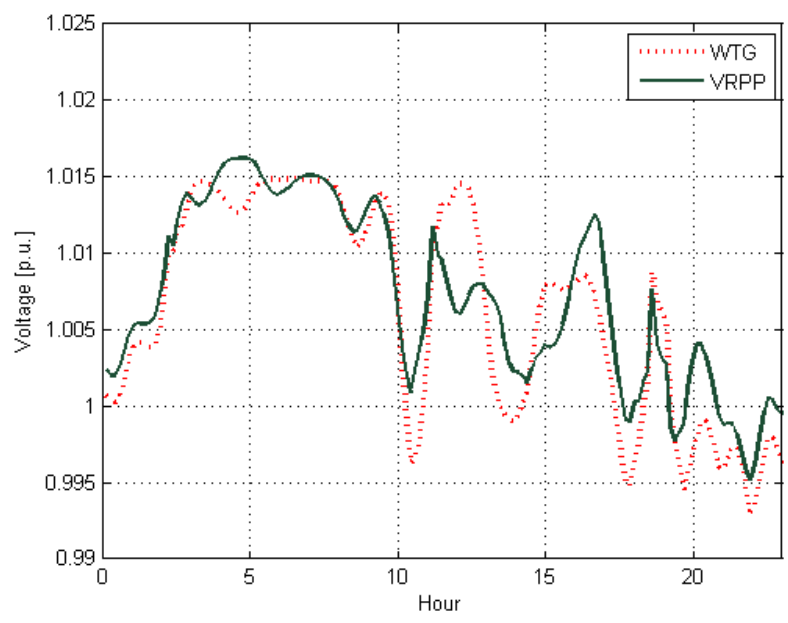

Figure 8. Voltage profile in the PCC for a typical day
The average value of the voltage and its standard deviation for the whole period simulated are presented in Table 2. Once again the VRPP configuration shows a better voltage profile, both in terms of mean voltage and its fluctuations.

TABLE II. VOLTAGE PROFILE STATISTICS IN THE PCC

\begin{tabular}{|c|c|c|}
\hline & Average Voltage [pu] & $\boldsymbol{\sigma}_{\text {voltage }}[\mathbf{p u}]$ \\
\hline Only WTGs & 1.011 & 0.0058 \\
\hline VRPP & 1.007 & 0.0033 \\
\hline
\end{tabular}

The step changes of power produced for the pure wind farm and for the VRPP are presented in Fig. 9 and 10 respectively while their standard deviations is presented in Table 3 All of them were obtained for three time horizons: 30 minutes, 1 hour and 4 hours.

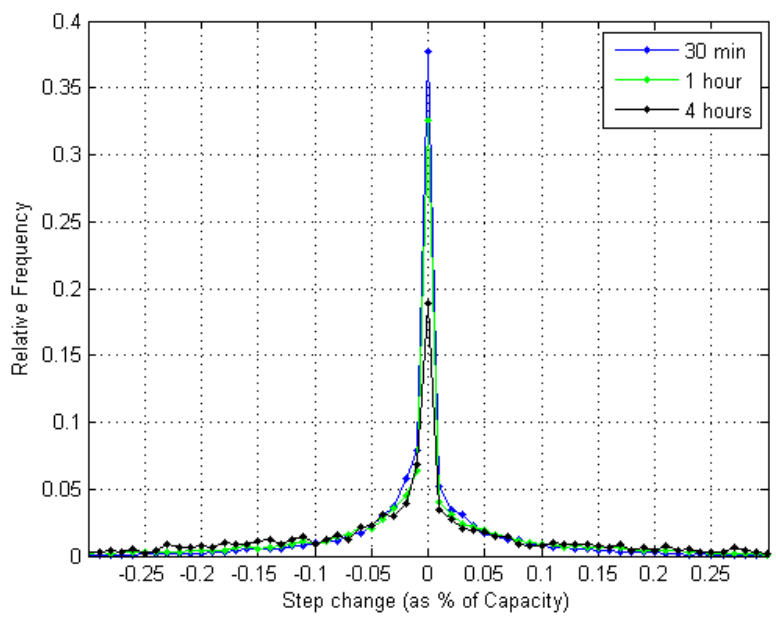

Figure 9. WTG power changes within 3 different time intervals

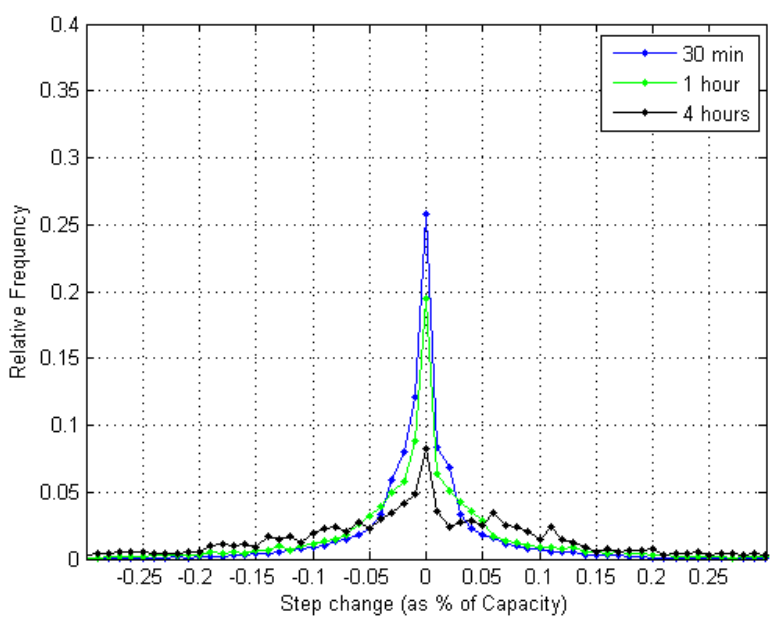

Figure 10. VRPP power changes within 3 different time intervals

TABLE III. STANDARD DEVIATION OF POWER FLUCTIATIONS

\begin{tabular}{|c|c|c|c|c|}
\hline Time & $\boldsymbol{\sigma}_{\text {VRPP }}$ & $\mathbf{3}_{\text {VRPP }}$ & $\boldsymbol{\sigma}_{\text {WTG }}$ & 3 $_{\text {WTG }}$ \\
\hline 30 min & 0.0593 & 0.1778 & 0.0729 & 0.2188 \\
\hline 1 hour & 0.0936 & 0.2809 & 0.1147 & 0.3442 \\
\hline 4 hours & 0.1530 & 0.4589 & 0.1830 & 0.5489 \\
\hline
\end{tabular}


Assuming that the power changes obey a Gaussian distribution, 68 percent of power changes are within $\pm \sigma$ and 99.7 percent are within $\pm 3 \sigma$. That means, e.g. that only 0.3 percent of the time power changes within 30 minutes for the VRPP is greater than 0.1778 of installed capacity.

\section{CONCLUSION}

A case study developing the Virtual Renewable Power Plant (VRPP) concept was carried out taking advantage of the Portuguese legislation to install $20 \%$ of overcapacity in wind farms. This paper aimed to evaluate the addition of PV overcapacity, instead of using the common approach of installing more turbines. A time domain model with typical reference data series was used to simulate a hybrid Virtual VRPP and assessing its advantages in terms of the local grid power quality and the DSO operation.

Several positive impacts both for RES developers and to the system operators were identified. For the developers, the result of adding $2 \mathrm{MWp}$ of $\mathrm{PV}$ to an $8 \mathrm{MW}$-wind plant is a direct increase from $24.0 \%$ to $29.3 \%$ in the capacity factor, for the same electrical infrastructures. Moreover, from the system's management point of view, the combined VRPP daily production profiles correlates much better with the average daily load profile (0.82) than WTG (0.41) or PV (0.54) alone.

The voltage fluctuations (that have a direct impact in local grid power quality) were characterized at the point of common coupling with the existing grid (PCC). The results obtained show an added smoothing effect in the hybrid VRPP voltage's fluctuation $\left(\sigma_{\text {voltage }}=0.0033 \mathrm{pu}\right)$ when compared to the standard initial wind plant $\left(\sigma_{\text {voltage }}=0.0058 \mathrm{pu}\right)$. Power fluctuations were also smoothed: for instance, hourly standard deviation was reduced from 0.1147 (WTG) to 0.0936 (VRPP).

Further studies on the VRPP concept including: (a) storage; (b) RES units with some power regulation capability (such as biomass or concentrated solar power - CSP plants), and (c) power quality issues (such as flicker and the harmonic distortion) should be developed to assess the full potential of these combined virtual plants. Still, the current work enables to conclude on the VRPP economical (through a clear increase in the capacity factor) and technical (a reduction of the voltage fluctuations) advantages in similar situations where the characteristics of the RES resources are complementary.

\section{REFERENCES}

[1] A. Estanqueiro, "Impact of Wind Generation Fluctuation in the Design and Operation of Power Systems.," in 7th international Workshop on Large Scale Integration of Wind Power and on Transmission Networks for Offshore Wind Farms, Madrid, 2008, p. 7.

[2] N. H. Lipman et al., "Fluctuations in the output from wind turbine clusters," Wind Engineering, vol. 4, no. 1, pp. 1-7, 1980.

[3] Tomonobu Senjyu et al., "Output Power Leveling of Wind Turbine Generator for All Operating Regions by Pitch Angle Control," IEEE Transactions on Energy Conversion, vol. 21, no. 2, pp. 467-475, June 2006.
[4] J. E. S. de Haan, J. Frunt, and W. L. Kling, "Mitigation of Wind Power Fluctuations in Smart Grids.," in 2010 IEEE PES Innovative Smart Grid Technologies Conference Europe (ISGT Europe), 2010, pp. 1-8.

[5] A. Estanqueiro, "The future energy mix paradigm: How to embed large amounts of wind generation while preserving the robustness and quality of the power systems.," in Wind Power, S. M. Muyeen, Ed., 2010, pp. 499-521.

[6] DL 51/2010. (2010) DR 98/2010 SÉRIE I DE 2010-05-20. [Online]. http://dre.pt

[7] Kenji Otani, Jyunya Minowa, and Kosuke Kurokawa, "Study on areal solar irradiance for analysing areally-totalized PV systems," Solar Energy Materials and Solar Cells, vol. 47, pp. 281-288, Oct. 1997.

[8] E. Wiemken, H. G. Beyer, W. Heydenreich, and K. Kiefer, "Power characteristics of PV ensembles:Experiences from the combined power production of 100 grid connected PV systems distributed over the area of Germany," Solar Energy, vol. 70, no. 6, pp. 513-528, 2001.

[9] Andrew Mills et al., "Understanding Variability and Uncertainty of Photovoltaics for Integration with the Electric Power System", The Electricity Journal, Dec. 2009.

[10] Joakim Widén, "Correlations between large-scale solar and wind power in a future scenario for Sweden," IEEE Transactions on Sustainable Energy, vol. 2, no. 2, pp. 177-184, April 2011.

[11] Dominik Heide et al., "Seasonal optimal mix of wind and solar power in a future, highly renewable Europe," Renewable Energy, vol. 35, pp. 2483-2489, 2010.

[12] H. Lund, "Large-sclae integration of optimal combinations of PV, wind and wave power into the electricity supply," Renewable Energy, vol. 31, pp. 503-515, Apr. 2006.

[13] A. G. Davenport, "The spectrum of horizontal gustiness near the ground in high winds.," Quarterly Journal Royal Meteorological Society, no. 87, pp. 194-211, 1961.

[14] W. Q. Jeffries, D. G. Infield, and J. Manwell, "Limitations and Recomendations Regarding the Shinozuka Method for Simulating Wind Data," Wind engineering, vol. 15, no. 3, pp. 147-154, 1991.

[15] Ricardo Aguiar, "Manual de Instalação e Utilização do software SolTerm - versão 1.5," Laboratório Nacional de Energia e Geologia LNEG, Lisboa, Software Manual 2007.

[16] Siemens Energy, Inc, PSS/E 32.0.5 Manual:: Siemens Power Technologies International, 2010.

[17] Robert E. Wilson, "Aerodynamic Behavior of Wind Turbines," in Wind Turbine Technology - Fundamental concepts of wind turbine engineering, David A. Spera, Ed. New York, USA: ASME, 1994, ch. 5, pp. $215-282$.

[18] J. G. Slootweg, S. W. H. de Haan, H. Polinder, and W. L. Kling, "General Model for Representing Variable Speed Wind Turbines in Power System Dynamics Simulations," IEEE Transactions on Power Systems, vol. 18, no. 1, pp. 144-151, Fev. 2003.

[19] Kara Clark, Nicholas W. Miller, and Reigh Walling, "Modeling of GE Solar Photovoltaic Plants for Grid Studies-v1.1," GE Energy, Schenectady, NY, 2010. 